\title{
Kadın Futsal Oyuncularında Motorik Performans İlişsisinin İncelenmesi
}

\section{Examining the Relationship Between Motoric Performance in Female Futsal}

\author{
Players
}

\author{
ORIJIINAL ARAŞTIRMA/ \\ ORIGINAL RESEARCH \\ Yasemin $\mathrm{ARI}^{1 \dagger}$, \\ Asım TUNÇEL ${ }^{2}$, \\ ${ }^{1}$ Tekirdağ Namık Kemal Üniversitesi, \\ Tekirdağ \\ https://orcid.org/0000-0002-1241-1347 \\ ${ }^{2}$ Tekirdağ Namık Kemal Üniversitesi, \\ Tekirdağ \\ https://orcid.org/0000-0003-1182-4497
}

$\ddot{O} \mathbf{z}$

$\mathrm{Bu}$ çalışmanın amacı kadın futsal oyuncularının motorik performans ilişkisini incelemektir. Çalışmaya 19-22 yaş arası toplam 9 kadın futsal oyuncusu gönüllü olarak katıldı. Sporcuların dayanıklılık performanslarını belirlemek için yo-yo aralıklı toparlanma testi I (YIRT I) ile ivmelenme, sürat, çeviklik ve dikey sıçrama testleri uygulandı. Verilerin normal dağılıma uygunlukları için 'Shapiro-Wilk' testi yapıldı. Verilerin normal dağılım göstermediği bulundu. $\mathrm{Bu}$ nedenle normal dağglım göstermeyen verilerin korelasyon analizinde 'Spearman Sira Korelasyon Katsayısı' kullanıldı. İstatistiksel anlamlılık için eşik değer olarak $0.05-0.01 \mathrm{p}$ değeri belirlendi. YIRT1 ile ivmelenme, sürat, çeviklik ve dikey sıçrama performansları arasında istatistiksel anlamda ilişki olmadığ tespit edildi $(\mathrm{p}>0.05)$. Sonuç olarak, bu çalışmada kadın futsal oyuncuların motorik performansları arasında ilişki olmadığı bulundu. Anahtar Kelimeler: Motorik Performans, Yo-Yo Aralıklı Toparlanma Testi, Sürat, Çeviklik.

\section{Yayın Bilgisi}

Gönderi Tarihi: 16.09.2020

Kabul Tarihi: 24.11.2020

Online Yayın Tarihi: 31.12.2020

DOI: 10.33459 cbubesbd. 795774

\begin{abstract}
The aim of this study is to examine the motor performance relationship of female futsal players. To work participated voluntarily 9 female futsal players between the ages of 19-22. In order to determine the endurance performance of the athletes, the yo-yo intermittent recovery test I (YIRT I) and acceleration, speed, agility and vertical jump tests were applied. The 'Shapiro-Wilk' test was conducted for the normal distribution of the data. It was found that the data were not normally distributed. For this reason, "Spearman Rank Correlation Coefficient" was used in the correlation analysis of the data that did not show normal distribution. Threshold value for statistical significance was determined as $0.05-0.01 \mathrm{p}$. It has been determined that there is no statistical relationship between YIRT I and acceleration, speed, agility and vertical jump performances $(\mathrm{p}>0.05)$. As a result, it was found in this study that there is no relationship between the motor performance of female futsal players.

Keywords: Motoric Performance, Yo-Yo Intermittent Recovery Test, Speed, Agility.
\end{abstract}

\footnotetext{
†Sorumlu yazar: Yasemin Arı, yaseminari88@gmail.com
} 


\section{GíRiş}

Federation de Football Association (FIFA) tarafından tanınan resmi kapalı alan futbolu olan futsal (Castagna, D’Ottavio, Granda-Vera ve Barbero-Alvarez, 2009), $20 \times 40 \mathrm{~m}$ alanda oynanmaktadır (Ruiz-Pérez ve ark., 2019). Futsal maçı 20 dakikalık iki yarıdan oluşur ve bazı etkinliklerde (fauller, saha dışı, vb.) süre durdurulmaktadır. Bu nedenle bir futsal maç süresi, planlanan toplam 40 dakikadan \% 75-85 daha uzun süre oynandığı anlamına gelmektedir (Barbero-Alvarez, Soto, Barbero-Alvarez ve Granda-Vera, 2008). Takımların her devrede bir mola (1 dakika) kullanmasına izin verilir ve resmi müsabakalarda devre arasında takımların 10 dakikalık mola hakkı bulunmaktadır (Barbero-Alvarez ve ark., 2015). Futsal oyun kurallarının sonucu olarak, bu sporda iyi gelişmiş anaerobik yollar ile birlikte yüksek aerobik uygunluk performansı önemlidir (Barbero-Alvarez ve ark., 2015; Castagna ve Barbero-Alvarez, 2010).

Sporcularda aerobik kapasitenin geliştirilmesi, bir oyun sırasında performansı belirleyen faktörlerden biridir. $\mathrm{Bu}$ nedenle, futsal oyuncularının kardiyovasküler direncinin arttırılması önemle ele alınması gerekmektedir (Lima, Silva ve Souza, 2005). Bir maç boyunca, oyuncuların 2.5 - $4.3 \mathrm{~km}$ arasında mesafeyi kat ettikleri bilinmektedir (Dogramaci, Watsford ve Murphy, 2015). Bununla birlikte futsal oyuncuları dakika başına ortalama 9 aktivite gerçekleştirmekte ve her 23 saniyede bir yüksek yoğunlukta çaba harcamaktadırlar. Ayrıca, futsal oyununun ortalama yoğunluğu maksimum kalp hızının ( $\left.\mathrm{KAH}_{\text {maks }}\right) \quad \% \quad 85-90$ ve $\mathrm{VO}_{2 \max }$ 1n $\% 75$ olduğunu göstermektedir. Enerji ağırlıklı olarak aerobik sistemden elde edilir, ancak yüksek yoğunluklu çabalar sırasında birincil enerji katkısı anaerobik metabolizmadan kaynaklanmaktadır (BarberoAlvarez ve ark., 2015). Maç analizi ve kalp atış hızı izleme çalışmaları, futsalın aerobik ve anaerobik kapasite gerektiren, aralıklı ve yüksek yoğunluklu bir oyun olduğunu göstermektedir (Barbero-Alvarez, D’Ottavio, Granda-Vera ve Castagna, 2009). Aynı zamanda, futsalda bir oyuncunun aralıklı dayanıklılık, sprint yeteneği, çeviklik ve anaerobik kapasitesiye sahip olması ve bu kapasiteyi geliştirmesi gerektirmektedir (Naser, Ali ve Macadam, 2017).

Futsal oyununun büyük bir bölümü, aralıklı ve yüksek yoğunlukta devam ettiği için kas enerjisi anaerobik glikoliz tarafından oluşturulmaktadır (Alvurdu, Köse ve Cinemre, 2016). Futsalda anaerobik sistem, sporcuların başarısında ve yüksek performans gösterebilmelerinde 
önemlidir. Müsabaka boyunca bir futsal oyuncusu, dar oyun alanında hızlı bir şekilde yer değiştiren, iyi bir teknik beceri ve taktik oyun sergileyen, birebir oyunda etkili olan, hücum ve savunmada toplu ve topsuz mesafe kat eden ve bu becerileri \% 80-100'e yakın tempoyla gerçekleştirebilen kişidir. Bu nedenle futsal oyuncularının iyi bir anaerobik kapasiteye sahip olmaları gerekmektedir (Erdem ve Yazar, 2019).

Ayrıca, hız ve çeviklik birçok sporda performansı etkileyen önemli beceriler olarak kabul edilmektedir (Çakır, 2019). Little ve Williams (2005) oyun sırasında gerçekleşen yüksek hızlı hareketler, düz sprint bileşenleri (hızlanma ve maksimum hız) ve çeviklik gerektiren eylemler olarak sınıflandırılabileceğini vurgulamıştır. Bir futsal maçı sırasındaki etkinliklerin ve eylemlerin çevikliği, sporcunun farklı uyaranlara mümkün olduğunca hızlı ve etkili tepki vermeye hazır olmasını gerektirmektedir (Lima ve ark., 2005).

Futsal oyununun yapısında, hem aerobik hem de anaerobik enerji sistemleri, özellikle fosfojen sistemi kullanılmaktadır (Naser ve ark., 2017). Son yıllarda popülaritesi artan futsal oyunu ile ilgili araştırmalar incelendiğinde, kadın futsal oyuncularının performans özelliklerine ilişkin mevcut literatürün kapsamlı olmadığı görülmektedir. Bundan dolayı çalışmaları karşılaştırmayı ve ayrıntılı sonuçlar çıkarmayı zorlaştırmaktadır. Kadın futsal oyunuyla ilgili daha fazla araştırma, spor bilimciler ve antrenörler için önemlidir. Bu gerçekler 1şı̆̆ında çalışmada, kadın futsal oyuncularında motorik performansları arasındaki ilişkinin değerlendirilmesi amaçlanmıştır.

\section{YÖNTEM}

\section{Çalışma Grubu}

Bu araştırmaya Tekirdağ Namık Kemal Üniversitesi futsal takımında oynayan gönüllü 9 kadın futsal oyuncusu (yaş ortalamaları 20.22 $.97 \mathrm{y}$ 1, boy ortalamaları $165.44 \pm 7.36 \mathrm{~cm}$, vücut ağırlığı ortalamaları $57.71 \pm 7.54 \mathrm{~kg}$, beden kütle indeksi $21.05 \pm 1.95 \mathrm{~kg} \cdot \mathrm{m}^{-2}$ ) katılmıştır. Çalışmaya katılanlara ölçümlerden önce 24 saat içinde bir fiziksel aktivite yapmamaları ve toparlanma günlerinde herhangi bir fiziksel egzersizden kaçınmaları söylenmiştir. Sporculara, ilk gün ivmelenme, $30 \mathrm{~m}$ sürat, 505 çeviklik ve dikey sıçrama testleri uygulanmış, ikinci gün YIRT1 testi 
yapılmıştır. Tüm testler 17.00-19.00 saatleri arasında gerçekleştirilmiştir. Testler başlamadan önce, oyuncular orta yoğunlukta aerobik egzersizler ve dinamik germe dahil olmak üzere genel bir grup ısınma (15 dakika) yapmışlardır.

\section{Veri Toplama Aracı}

Araştırma Etiği: Araştırma öncesinde, Atatürk Üniversitesi Spor Bilimleri Fakültesinin 12.06.2020 tarih ve 70400699/11.00-190066441 sayılı kararı ile çalışmanın Etik Onamı alınmıştır. Ayrıca çalışma grubunda yer alan katımcılar, araştırma ve araştırmada katılacakları testler hakkında bilgilendirilmiş; araştırmaya gönüllü olarak katılımlarını beyan ettikleri formlar katılımcılar tarafından imzalanmıştır.

İvmelenme: Katılımcılar, vücutları öne doğru eğilerek tetik çizgisinin $1 \mathrm{~m}$ arkasına yerleştirilmiştir. İvmelenme testi Microgate Witty fotosel kullanılarak ölçülmüştür. Her biri arasında 2 dakikalık dinlenme süresi olan $10 \mathrm{~m}$ ivmelenme koşusu yapılmıştır. Tekrarlanan iki test arasındaki en iyi performans kaydedilmiştir. İkinci deneme öncesi ve diğer test arasında anaerobik sistemin normale dönebilmesi için yeterli dinlenme süresi verilmiştir (Sekulic ve ark., 2019).

30 m Sürat: Sporcuların $30 \mathrm{~m}$ koşu süreleri futsal sahasında Microgate Witty fotosel kullanılarak ölçülmüştür. Her katılımcı, aralarında 3 dakikalık bir dinlenme süresiyle iki hızlı koşu testi gerçekleştirmiş̧tir. Tekrarlanan iki sürat testi arasındaki en iyi performans kaydedilmiştir (Rakovic, Paulsen, Helland, Eriksrud ve Haugen, 2018).

505 Çeviklik: Sporcuya başlangıç çizgisinden başlayarak 10 metrelik bir yaklaşma koşusunun ardından 5 metrelik bir mesafenin gidiş ve dönüş kapısını geçene kadar hızlı koşması söylenmiştir. Parkur kurulduktan sonra $5 \mathrm{~m}$ çizgisinin üzerine Microgate Witty fotosel kronometre sisteminin hem start hem de stop kapıları yerleştirilmiştir. Sporcu sağdan veya soldan dönmüştür ve sonra stop kapısına doğru koşmuştur. Bu test 3-4 dakika ara ile iki kez tekrarlanmış ve en iyi skor değerlendirmeye alınmıştır (Hazır, Mahir ve Açıkada, 2010; Karacabey, 2013).

Dikey Sıçrama Testi: Katılımcılar belirlenen $40 \times 40 \mathrm{~cm}$ kare bir alan içerisinde konumlandırılmıştır. Alanın tam karşısına katılımcıyı görecek şekilde kamera yerleştirilmiş ve katılımcıdan eller serbest şekilde aktif sıçrama yapması istenmiştir. Dizleri büküldüğünde, 
bacaklar kalçadan fleksiyon yaptığında ve işaretli alan çizgileri üzerine veya dışarı konma yapıldığında sıçrama geçersiz sayılmıştır ve katılımcıya 3 dakika dinlenme yaptırıldıktan sonra tekrar sıçrama yaptırılmıştır. Her katılımcıya 2 kez başarılı sıçrama yaptırılmış ve başarılı olarak yapılan sıçramalar kameraya kaydedilmiştir. Görüntüler daha sonra bilgisayar ortamına SD card vasıtası ile aktarılmıştır. Aktarılan görüntülerden katılımcıların uçuş süresi Kinovea 0.8.15 programı vasıtasıyla hesaplanmıştır. Uçuş süreleri belirlenen katılımcıların sıçrama yükseklikleri formül-1 ile hesaplanmıştır.

$$
\begin{aligned}
& \text { formül-1 } \quad h=\frac{1}{2} g t^{2} \\
& h=\text { yükseklik } g=9.806 \quad t=\text { Uçuş süresi }
\end{aligned}
$$

Yo-Yo Aralıklı Toparlanma Testi I (YIRT I): Katılımcılar şekil-1'de belirtilen alanda 2 numaralı başlangıç noktasından sinyal sesi ile koşmaya başlamışlardır ve 3 numaralı çizgiye basıp geri dönerek diğer sinyal sesine kadar 2 numaralı çizgiye koşarak bir turu bitirmişlerdir. Her turdan sonra 10 saniye dinlenme aralı̆̆ vardır ve bu aralıkta katılımcılar 1 numaralı çizgiye jog koşusu yaparak dönmüş ve diğer koşu hızı için hazırlanmışlardır. Sinyal sesini duyduklarında tekrardan aynı şekilde koşmaya başlamışlardır. Eğer katılımcı, sinyal sesi duyulduğunda çizgiye gelemediyse 1 hata olarak kabul edilmiş ve 2 hata yapan katılımcının testi sonlandırılmıştır. Sinyal sesi $10 \mathrm{~km} / \mathrm{s}$ hızla başlatılmış ve test protokolüne bağlı olarak koşu hızı artırılmıştır. Katılımcıların kalp atım hızların kaydetmek için Polar marka (M400, Finlandiya) saat ve her saat ile eşleştirilmiş göğüs bandı kullanılmıştır. Katılımcıların koşu mesafeleri ve kalp atım hızları kaydedilmiştir. Katılımcılara artık güçlerinin kalmadığ ve gidemeyeceklerini hissettiklerinde testi sonlandırabilecekleri söylenmiştir (Karsten ve ark., 2016).

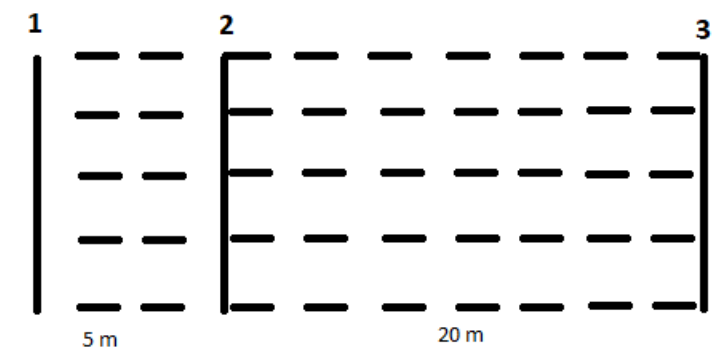

Şekil 1 Yo-Yo Aralıklı Toparlanma Test I (YIRT I) 


\section{Verilerin Analizi}

Tüm istatistiksel analizler SPSS sürüm 18.0 yazılımı (Sosyal Bilimler için İstatistik Paketi; SPSS Inc., Chicago, IL, USA) kullanılarak yapılmıştır. Veriler, tanımlayıcı istatistiklerle analiz yapılmıştır ve sonuçlar ortalama, standart sapma, minimum ve maksimum değerler olarak rapor edilmiştir. Çalışmada kullanılan her bir değişkendeki verilerin normal dağılım gösterip göstermediği 'Shapiro-Wilk' analizi ile belirlenmiştir. Verilerin normal dağılım göstermediği bulunmuştur. Bu nedenle anaerobik ve aerobik performansları arasındaki ilişki 'Spearman Sıra Korelasyon Katsayısı' kullanılarak tespit edilmiştir. Anlamlılık değeri $\mathrm{p}<0.05$ olarak kabul edilmiştir. Korelasyon katsayısı değerleri; 0.00-0.40 güvenilir değil, 0.41-0.60 düşük güvenirlik, 0.61-0.80 orta düzeyde güvenilir, 0.81-1.00 yüksek düzeyde güvenilir (Özdamar, 2002) katsayılarına göre yorumlanmıştır.

\section{BULGULAR}

\section{Demografik Bulgular}

Araştırmada elde edilen verilerin demografik dağılımı Tablo 1'de verilmiştir.

Tablo 1.Sporcuların demografik özellikleri

\begin{tabular}{lrrrr}
\hline Değişkenler & Ortalama & Ss & Minimum & Maksimum \\
\hline Yaş (yıl) & 20.22 & .97 & 19 & 22 \\
Boy uzunluğu (cm) & 165.44 & 7.36 & 155.00 & 175.00 \\
Vücut ağırlı̆̆ $(\mathrm{kg})$ & 57.71 & 7.54 & 47.00 & 68.10 \\
Vücut kütle indeksi $\left({\left.\mathrm{kg} . \mathrm{m}^{-2}\right)}^{2}\right.$ & 21.05 & 1.95 & 17.60 & 24.40 \\
\hline
\end{tabular}

$\mathrm{cm}=$ santimetre, $\mathrm{kg}=$ kilogram, $\mathrm{kg} \cdot \mathrm{m}^{-2}=$ kilogram $/$ metre kare

Ölçümlerden elde edilen performans değerleri tablo 2'de, gösterilmiştir.

Tablo 2. Sporcuların testler sonucu elde edilen performans değerleri

\begin{tabular}{|c|c|c|c|c|}
\hline Değişkenler & Ortalama & Ss & Minimum & Maksimum \\
\hline İvmelenme 10 m (sn) & 1.95 & .12 & 1.70 & 2.16 \\
\hline 30 m sürat (sn) & 5.01 & .25 & 4.71 & 5.38 \\
\hline 505 çeviklik testi (sn) & 2.69 & .22 & 2.48 & 3.18 \\
\hline Dikey Siçrama (cm) & 32.21 & 5.12 & 25.94 & 39.84 \\
\hline \multicolumn{5}{|l|}{ YIRT1 } \\
\hline - Mesafe (m) & 546.66 & 142.82 & 400.00 & 760.00 \\
\hline$-\mathrm{VO}_{2 \max }\left(\mathrm{ml} . \mathrm{kg} \mathrm{dk}^{-1}\right)$ & 40.99 & 1.19 & 39.76 & 42.78 \\
\hline$-\mathrm{KAH}_{\max }(\mathrm{atım} / \mathrm{dk})$ & 191.66 & 6.40 & 181.00 & 203.00 \\
\hline
\end{tabular}


Ölçümlerden elde edilen performans değerleri arasındaki ilişki tablo 3’te yer almaktadır.

Tablo 3. Sporcuların performans test sonuçları arasındaki ilişkisi

\begin{tabular}{|c|c|c|c|c|c|}
\hline Değişkenler & $\begin{array}{r}\text { İvmelenme } \\
10 \mathrm{~m}(\mathrm{sn}) \\
\end{array}$ & $\begin{array}{r}30 \text { m sürat } \\
(\mathrm{sn})\end{array}$ & $\begin{array}{r}505 \text { çeviklik } \\
\text { (sn) }\end{array}$ & $\begin{array}{r}\text { Dikey sıçrama } \\
(\mathrm{cm})\end{array}$ & $\begin{array}{r}\text { YIRT1 } \\
(\mathbf{m}) \\
\end{array}$ \\
\hline İvmelenme $10 \mathrm{~m}$ (sn) & 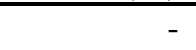 & .494 & -.117 & .110 & .386 \\
\hline $30 \mathrm{~m}$ sürat $(\mathrm{sn})$ & & - & .150 & -.437 & .421 \\
\hline 505 çeviklik testi (sn) & & & - & -.479 & -.135 \\
\hline Dikey sıçrama $(\mathrm{cm})$ & & & & - & .421 \\
\hline YIRT1 (m) & & & & & - \\
\hline
\end{tabular}

Elde edilen verilere göre, ivmelenme, sürat, çeviklik, sıçrama ve YIRT1 performansları arasında istatistiksel anlamda ilişki bulunmamıştır ( $\mathrm{p}>0.05)$.

\section{TARTIŞMA VE SONUÇ}

Futsal oyununda her 3.3 saniyede yüksek şiddetli aktiviteler yapılırken (Burns, 2003), bu aktiviteler ile birlikte oyuncuların fiziksel, taktik ve teknik özelliklerinin üst düzey olması beklenir (Naser ve ark., 2017). Pas, şut, dripling gibi teknik özelliklerin kaliteli olması gerekirken, bu teknik becerileri etkili bir şekilde sergilemek için iyi bir aerobik dayanıklılık kapasitesi, sprint becerisi ve bacak gücüne ihtiyaç vardır (Duarte, Batalha, Falgado ve Sampaio, 2009; Naser ve ark., 2017). Bu doğrultuda, bu çalışmada kadın futsalcıların fizyolojik özelliklerinin birbiriyle olan ilişkisinin incelenmesi amaçlanmıştır. Çalışma bulgularına göre, katılımcılardan elde edilen verilerin korelasyon analizinde dayanıklılık, sürat, çeviklik ve sıçrama özellikleri arasında ilişki olmadığ 1 bulunmuştur.

Dayanıklılık, sürat, çeviklik, anaerobik güç gibi parametrelerin futsal performans çıktısı açısından incelenmesi son yıllarda araştırmacıların ilgisini çekmiştir (Barbero ve ark., 2015; Ramos-Campo, Rubio-Arias, Carrasco-Poyatos ve Alcaraz, 2016). Futsal oyunu özelinde dayanıkl1lık ve sürat becerilerinin oyunun iki önemli özelliği olduğu belirtilmektedir (Burns, 2003). Gelişmiş bir dayanıklılık özelliği oyuncunun teknik performans çıktısına katkı sağlamaktadır (Duarte ve ark., 2009; Naser ve ark., 2017). Bununla birlikte aerobik ve anaerobik özellikler oynanan seviyeye göre değişiklik göstermektedir (Moore, Bullough, Goldsmith ve Edmondson, 2014; Lockie ve ark., 2016). 
Ramos-Campo ve ark. (2016) elit ve sub-elit kadın futsalcıların $30 \mathrm{~m}$ sürat test sonuçlarını

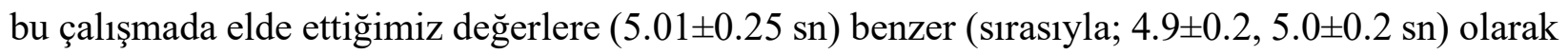
raporlamışlar ve oynanan seviyeye göre bir farklılık tespit etmemişlerdir. Yine aynı çalışmada sıçrama test sonuçlarında aktif ve pasif sıçrama değerlerinde seviyeye göre farklılık olmadığını rapor etmişlerdir. Rapor edilen aktif sıçrama değerlerinin (sırasıyla: $26.7 \pm 0.3 \mathrm{~cm}, 24.03 \pm 0.3 \mathrm{~cm}$ ) bu çalışmada elde edilen değerlerden $(32.21 \pm 5.12 \mathrm{~cm})$ daha az olduğu bulunmuştur. Galy ve ark. (2015) futsal oyuncularının performanslarını inceledikleri araştırmada, $10 \mathrm{~m}$ sürat test sonuçları sırasıyla $2.18 \pm 0.12 \mathrm{sn}, 2.13 \pm 0.13 \mathrm{sn}, 30 \mathrm{~m}$ sürat test sonuçları sırasıyla $4.72 \pm 0.17 \mathrm{sn}, 4.80 \pm 0.15$ sn, aktif sıçrama test sonuçları ise sırasıyla: $50.44 \pm 5.88 \mathrm{~cm}, 45.16 \pm 4.34 \mathrm{~cm}, \mathrm{VO}_{2 \text { maks }}$ değerleri

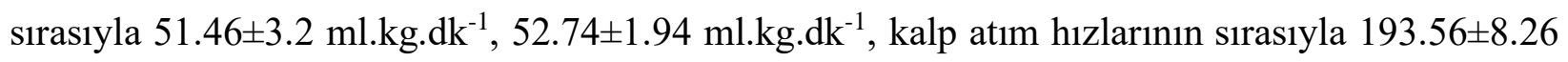
atım/dk, $187.88 \pm 12.68 \mathrm{atım} / \mathrm{dk}$ olarak belirtmişlerdir. Belirtilen atım hızları, $\mathrm{VO}_{2 \text { maks }}$ ve sıçrama değerleri bu çalışmadaki değerlere benzerken, sürat değerleri bu çalışma bulgularından daha düşüktür. Bununla birlikte kalp atım sayılarının birbirine benzer olduğu bulunmuştur.

Lockie ve ark. (2016)'nın farklı iki ligde oynayan kadın futbol oyuncularının çeviklik ve yön değiştirmeli koşu ilişkilerini inceledikleri çalışmada, 1 ve 2'nci lig oyuncularının 505 çeviklik test sonuçları sırasıyla $2.40 \pm 0.10 \mathrm{sn}, 2.60 \pm 0.11 \mathrm{sn}, 10 \mathrm{~m}$ sprint değerleri ise sirasıyla $1.91 \pm 0.16$ sn, $1.89 \pm 0.17$ sn olarak tespit etmişlerdir. Başkaya, Ünveren ve Karavelioğlu (2018) kadın futbol ve futsal oyuncularının motor performans özelliklerinin karşılaştırıldığı farklı bir çalışmada kadın futsalcıların $10 \mathrm{~m}$ ve $30 \mathrm{~m}$ sürat değerleri sırasıyla $1.62 \pm 0.08 \mathrm{sn}, 4.31 \pm 0.35 \mathrm{sn}$ bulmuşlar ve bu çalışmada elde edilen verilerden daha yüksek veriler raporlamışlardır. Aynı şekilde YIRT1 koşu mesafe değerleri Başkaya ve ark. (2018)'nın çalışmasında daha yüksek olduğu gözlenirken sıçrama yükseklik değerleri bizim çalışmamızdaki değerlerden daha düşük olduğu tespit edilmiştir. Bu farklılıkların araştırmada yer alan katılımcıların daha tecrübesiz oyunculardan oluşması ile açıklanabilir. Bu da Lockie ve ark. (2016)'nın oynanan seviyeye göre performans özelliklerinde farkl1lık oluştuğu sonucunu desteklemektedir.

Futsal oyuncularının profesyonel seviyedeki karşılaşmalarda 5000 metre, amatör seviyedeki karşılaşmalarda ise 4500 metre mesafe kat ettikleri ve bunun da basketbol ve hentbol oyununa benzer sonuçlar olduğu ifade edilmektedir (Gioldasis, 2016). Nikolaidis ve ark. (2015) basketbolcularda yaptıkları çalışmada $10 \mathrm{~m}$ sürat ile sıçrama performansı arasında ilişki bulamamışken $20 \mathrm{~m}$ sürat performansı ile sıçrama arasında ilişki bulmuşlardır. Hentbol 
oyuncularında ise aerobik performans ile $30 \mathrm{~m}$ sprint, çeviklik, sıçrama performansları arasında düşük ilişki olduğu raporlanmıştır (Wagner, Sperl, Bell ve Von Duvillard, 2019). Lockie ve ark. (2016) elit kadın futbolcularda YIRT1, YIRT2, 30 m sürat, pro-çeviklik ve 60 m mekik koşusu testleri arasındaki ilişkiyi inceledikleri çalışmada $30 \mathrm{~m}$ sürat, pro-çeviklik ve $60 \mathrm{~m}$ mekik koşusu ile yoyo testleri arasında ilişki olmadığını belirtmişlerdir.

Futsalda yüksek yoğunluklu defanstan hücuma, hücumdan defansa geçme gibi aksiyonlar fizyolojik özellikleri tanımlamaktadır (Burns, 2003). Oyuncuların yüksek yoğunluklu bu aktiviteler içerisinde maksimum performans gösterebilmeleri dayanıklılık, sprint, çeviklik gibi özelliklerinin gelişmiş olması ile ilişkilidir. Bunun yanında müsabakada performans çıktısı üst düzey oyuncularda sprint yeteneği önemli faktörken, iyi bir çeviklik özelliği de rakibe üstünlük kurmak için gereklidir. Çeviklik hız, kuvvet, karar verme, çabukluk gibi birçok faktörden etkilenebilmektedir (Eroğlu, 2018). Dolayısıyla üst düzey performans açısından tüm bu belirtilen motorik özelliklerin birlikte gelişimi başarılı performans için kriter olmaktadır.

Sonuç olarak, bu çalışmada kadın futsalcıların dayanıklılık, sürat, çeviklik ve sıçrama performansları arasında ilişki olmadığı bulunmuştur. Kadın futsalcıların seviyelerine göre değerlendirildiği mevcut çalışmaların sonuçları bu araştırma bulguları ile benzerlik göstermektedir. Yapılan araştırmada, motorik performansları arasında ilişki bulunmaması katılımcı sayısının az olması ile açılanabilir. Bundan sonra yapılacak olan çalışmalarda motor performans çıktılarının birbiri ile olan ilişkisinin daha geniş örneklem grupları ve farklı seviyelerdeki oyuncular üzerinde incelenmesi, kadın futsalcıların performans gereksinimlerin anlaşılması ve geliştirilmesi açısından önemli olacaktır.

\section{KAYNAKLAR}

Alvurdu, S., Köse, M.G., \& Cinemre, Ş.A. (2016). Evaluation of the relationship between anaerobic power and repeated changeof-direction ability of futsal players. Gazi Journal of Physical Education and Sport Sciences, 21(1-4), 29-37.

Barbero-Alvarez, J.C., D’Ottavio, S., Vera, J.G., \& Castagna, C. (2009). Aerobic fitness in futsal players of different competitive level. Journal of Strength and Conditioning Research,23(7), 2163-2166.

Barbero-Alvarez, J.C., Soto, V.M., Barbero-Alvarez, V., \& Granda-Vera, J. (2008). Match analysis and heart rate of futsal players during competition. Journal of Sports Sciences, 26(1), 63-73. 
Arı, Y., Tunçel, A. (2020). Kadın futsal oyuncularında motorik performans ilişkisinin incelenmesi. CBÜ Beden Ĕ̈itimi ve Spor Bilimleri Dergisi, 15 (2), 68-78.

Barbero-Alvarez, J.C., Subiela, J.V., Granda-Vera, J., Castagna, C., Gómez, M., \& Del Coso, J. (2015). Aerobic fitness and performance in elite female futsal players. Biology of Sport, 32(4), 339-344.

Başkaya, G., Ünveren, A., \& Karavelioğlu, M.B. (2018). Comparison of some physiological and motoric characterictics of female soccer and futsal players. Niğde Üniversitesi Beden Ĕ̈itimi ve Spor Bilimleri Dergisi, 12(1), 12-20.

Burns, T. (2003). Holistic futsal: a total mind-body-spirit approach. New York: Lulu.

Castagna, C., \& Barbero-Alvarez, J.C. (2010). Physiological demands of an intermittent futsal-oriented high-intensity test. Journal of Strength and Conditioning Research, 24(9), 2322- 2329.

Castagna, C., D’Ottavio, S., Vera, J.G., \& Barbero-Alvarez, J.C. (2009). Match demands of professional futsal: A case study. Journal of Science and Medicine in Sport, 12(4), 490-494.

Çakır, E. (2019). Investigation of female soccer players performance values based on ambient temperature. Universal Journal of Educational Research, 7(1), 239-243.

Dogramaci, S.N., Watsford, M., \& Murphy, A. (2015). Activity profile differences between sub-elite futsal teams. International Journal of Exercise Science, 8(2), 112-123.

Duarte, R., Batalha, N., Falgado, H., \& Sampaio, J. (2009). Effects of exercise duration and number of players in heart rate responses and technical skills during futsal small-sided games. The Open Sports Sciences Journal, 2, 37-41.

Erdem, K., \& Yazar, M. (2019). Futsal antrenmanlarının 16-17 yaş erkek sporcularda sürat, çeviklik ve anaerobik dayanıklılığa etkisi. Spor Ë̆itim Dergisi, 3(3), 63-70.

Eroğlu, A.K. (2018). Farklı türdeki çeviklik çalışmalarının basketbolculardaki bazı fizyolojik parametrelere, motorsal yeteneklere ve teknik özelliklere etkisi. Ankara: Gece Akademi.

Galy, O., Zongo, P., Chamari, K., Chaouachi, A., Michalak, E., Dellal, A., Castagna, C., \& Hue, O. (2015). Anthropometric and physiological characteristics of Melanesian futsal players: A first approach to talent identification in Oceania. Biology of Sport, 32(2), 135-141. DOI: 10.5604/20831862.1140428

Gioldasis, A.(2016). A review of anthropometrical, physiological, psychological and training parameters of futsal. International Journal of Science Culture and Sport, 4(3), 240-259. Doi: 10.14486/IntJSCS500

Hazır, T., Mahir, Ö.F., \& Açıkada, C. (2010). Genç futbolcularda çeviklik ile vücut kompozisyonu ve anaerobik güç arasındaki ilişki. Spor Bilimleri Dergisi, 21(4), 146-153.

Karacabey, K. (2013). Sporda performans ve çeviklik testleri. International Journal of Human Sciences, 10(1), $1693-1704$. 
Arı, Y., Tunçel, A. (2020). Kadın futsal oyuncularında motorik performans ilişkisinin incelenmesi. CBÜ Beden Ĕ̈itimi ve Spor Bilimleri Dergisi, 15 (2), 68-78.

Karsten, B., Larumbe, E., Kandemir, G., Hazır, T., Klose, A., \& Naclerio, F. (2016). The effect of a 6-week strength training on critical velocity, anaerobik running distance, $30-\mathrm{m}$ sprint and yo-yo intermittent running test performances in male soccer players. Plos One, 11(3), 1-10.

Little, T., \& Williams, A.G. (2005). Specificity of acceleration, maximum speed, and agility in professional soccer players. Journal of Strength and Conditioning Research, 19(1), 76-78.

Lima, A.M.J., Silva, D.V.G., \& Souza, A.O.S. (2005). Correlation between direct and indirect $\mathrm{VO}_{2 m a x}$ measurements in indoor soccer players. Revista Brasileira de Medicina do Esporte, 11(3), 159-161.

Lockie, R., Jalilvand, F., Moreno, M.R., Orjalo, A.J., Risso, F.G., \& Nimphus, S. (2016). Yo-yo intermittent recovery test level 2 and its relationship with other typical soccer field tests in female collegiate soccer players. The Journal of Strength \& Conditioning Research, 31(10), 2667-2677.

Moore, R., Bullough, S., Goldsmith, S., \& Edmondson, L. (2014). A systematic review of futsal literature. American Journal of Sports Science and Medicine, 2(3), 108-116.

Naser, N., Ali, A., \& Macadam, P. (2017). Physical and physiological demands of futsal. Journal of Exercise Science \& Fitness, 15(2), 76-80.

Nikolaidis, P.T., Asadi, A., Santos, E.J., Calleja-González, J., Padulo, J., Chtourou, H., \& Zemkova, E. (2015). Relationship of body mass status with running and jumping performances in young basketball players. Muscles, Ligaments and Tendons Journal, 5(3), 187-194.

Özdamar, K. (2002). Paket programlar ile istatistiksel veri analizi. 4. Bask1, Kaan Kitabevi.

Rakovic, E., Paulsen, G., Helland, C., Eriksrud, O., \&Haugen, T. (2018). Theeffect of individualised sprint training in elite femaleteamsportathletes: a pilot study. Journal of Sports Sciences, 36(24), 2802-2808.

Ramos-Campo, D.J., Rubio-Arias, J.A., Carrasco-Poyatos, M., \&Alcaraz, P.E. (2016). Physicalperformance of elite andsubelite Spanish femalefutsalplayers. Biology of Sport, 33(3), 297. DOI: 10.5604/20831862.1212633

Ruiz-Pérez, I., López-Valenciano, A., Jiménez-Loaisa, A., Elvira, J.L., Croix, M.D.S., \& Ayala, F. (2019). Injury incidence, characteristics and burden among female sub-elite futsal players: A prospective study with three-year follow-up. PeerJ, 7, 1-21. https://doi.org/10.7717/peerj.7989

Sekulic, D., Foretic, N., Gilic, B., Esco, M.R., Hammami, R., Uljevic, O., Versic, S., \& Spasic, M. (2019). Importance of agility performance in professional futsal players; reliability and applicability of newly developed testing protocols. International Journal of Environmental Research and Public Health, 16(18), 3246. doi: 10.3390/ijerph16183246

Wagner, H., Sperl, B., Bell, J.W., \& Von Duvillard, S.P. (2019). Testing specific physical performance in male team handball players and the relationship to general tests in team sports. The Journal of Strength \& Conditioning Research, 33(4), 10561064 . 